This is a post-peer-review, pre-copyedit version of an article published in

Food Analytical Methods. The final authenticated version is available online at: http://dx.doi.org/10.1007/s12161-017-1111-z

\title{
An Analytical Simplification for Faster Determination of Fatty Acid Composition and Phytosterols in Seed Oils
}

Aída García-González ${ }^{1}$, Joaquín Velasco ${ }^{1}$, Leonardo Velasco ${ }^{2}$ and M. Victoria Ruiz-

$$
\text { Méndez }{ }^{1, *}
$$

${ }^{1}$ Instituto de la Grasa, Consejo Superior de Investigaciones Científicas (CSIC),

Campus Universidad Pablo de Olavide E46, Ctra. de Utrera km 1, 41013 Seville, Spain

${ }^{2}$ Instituto de Agricultura Sostenible, Consejo Superior de Investigaciones Científicas (CSIC), Alameda del Obispo s/n, 14004 Córdoba, Spain

*To whom correspondence should be addressed:

Telephone: $\quad+34954611550$

Fax: $\quad$ +34954616790

E-mail: mvruiz@ig.csic.es

ORCID: García-González A， http://orcid.org/0000-0002-2567-9916; Velasco J, http://orcid.org/0000-0003-4206-3037; Velasco L, http://orcid.org/0000-0003-4998-9406; RuizMéndez M V, http://orcid.org/0000-0003-0750-7915 


\section{Abstract}

The fatty acid composition and the amounts of individual and total sterols in vegetable oils are the main analyses applied in the food industry to establish the oil nature. While the fatty acid composition is a relatively simple, fast analysis, the determination of phytosterols requires a laborious and time-consuming sample preparation. Both methods require a relatively large amount of oil, which may be an important drawback when only small samples are available. In this study, an analytical procedure that combines the sample preparation of both determinations is proposed to analyze small amounts of seed oils. From a single sample preparation, the total analysis time was considerably shortened. By applying a total methylation, the triacylglycerols and free fatty acids were transformed into fatty acid methyl ester (FAME) derivatives. Likewise, free sterols were completely released from their conjugated forms. Then the derivatized oil was fractionated by solid-phase extraction into two fractions containing the FAME and free sterols, respectively. Both fractions were analyzed by gas-liquid chromatography. The analytical changes introduced provided reliable results for the main fatty acids and the major sterols in terms of accuracy and repeatability. Compared to the standard procedures, the time for sample preparation was reduced by half. In addition, it was much less laborious and required less volume of organic solvents, which reduced considerably the total cost of analysis and solvent waste. Consequently, the method proposed can be adopted as routine analysis in laboratories of oil quality control in the food industry.

\section{Keywords}

Phytosterols $\cdot$ Fatty acids $\cdot$ Seed oil $\cdot$ Solid-phase extraction $\cdot$ SPE 


\section{Introduction}

Vegetable oils are widely used in the food industry and their selection relies on their physical properties, price, and availability. The conformity control of a vegetable oil starts with a series of tests according to recommendations of certification and regulatory authorities, e.g., ISO, to ensure identity, quality, and safety. The cost of these measurements is high and can be further increased on the basis of the results obtained (Magnusson and Örnemark 2014). The fatty acid composition and the composition and total amount of desmethyl sterols in vegetable oils are the main analyses applied in the industry to identify the oil nature (Spencer et al. 1976; Gordon and Griffith 1992; Codex Alimentarius 2001). While the fatty acid composition is a relatively simple, fast analysis, the determination of desmethyl sterols, from now on phytosterols, is laborious and time-consuming.

Phytosterols form part of the unsaponifiable fraction, which is a minor, highly specific part of vegetable oils. They are steroid alcohols that occur in oils in free and conjugated forms, mainly sterols esterified with fatty acids, and others in minor amounts (Moreau et al. 2002; Kumar et al. 2016). The concentrations of phytosterols constitute an indicator of genuineness. For instance, brassica seed oils have a high content of brassicasterol, whereas olive oils are characterized by a high concentration of $\Delta 5$ avenasterol. Hence, phytosterols are often used as markers for the assessment of adulterated oils (Abidi 2001; Tena et al. 2015).

Although different chromatographic techniques have been proposed for the isolation, purification, separation, and detection of phytosterols (Abidi 2001; Lagarda et al. 2006), the standard analytical method used in oils is based on gas chromatography with flame ionization detection (GC-FID). The sample preparation consists of several steps, namely, saponification of the oil to transform the glyceridic compounds into free fatty 
acid (FFA) soaps, extraction of the unsaponifiable matter by liquid-liquid extraction, isolation of the phytosterols using thin-layer chromatography, and derivatization to trimethylsilyl ether derivatives. In the saponification step, the ester bound of sterol esters is broken and the free form is released. Consequently, the phytosterols are globally evaluated in their free forms. This method has been well described in different regulatory documents (EEC 1991; IUPAC 1992; ISO 1991, 1999; AOCS 1997). Despite its usefulness, it is widely recognized that the method is laborious, time-consuming, and wasteful in terms of reagents (Alberici et al., 2016).

Toivo et al. (1998) proposed the use of solid-phase extraction (SPE) to shorten the sample preparation time and to reduce the volume of organic solvents required in the analysis of sterols in edible fats and oils. After THE saponification of the oil, an internal standard dissolved in chloroform was added, an aliquot of the chloroform phase was withdrawn, the $\mathrm{pH}$ of the aliquot was adjusted with $\mathrm{HCl}$, and the sterols were separated by SPE using a non-polar C18 adsorbent.

A common drawback in the determinations of fatty acid composition and sterols is that a relatively large amount of oil is required, which may be a serious obstacle when small amounts are to be analyzed. Such is the case of plant breeding studies in which only a reduced number of seeds from a single plant can be used for the analyses since the rest of the seeds have to be used to continue the selection. In this respect, Garcés and Mancha (1993) proposed a procedure for the determination of fatty acid composition from small amounts of seed samples. This was based on digestion of fresh tissue at acid conditions, transmethylation of lipids, and extraction of the FAME derivatives in just one step. Similarly, Fernández-Cuesta et al. (2012) proposed a method for the analysis of phytosterols directly in small samples of sunflower seeds. It consisted in alkaline 
hydrolysis, extraction of the unsaponifiable fraction, silanization and direct analysis by gas-liquid chromatography.

The objective of the present work was to propose an analytical simplification of the standard determinations of the fatty acid composition and phytosterols in seed oils to help improve not only the control analyses performed in the industrial sector, but also in plant-breeding studies, in which small amounts of sample are to be analyzed. The improvements introduced consisted in reducing the amount of sample and shortening the sample preparation time. The saponification of the oil, the subsequent extraction of the unsaponifiable fraction, and the separation by TLC in the analysis of phytosterols were replaced with complete methylation of the oil to obtain the FAME derivatives and separation by SPE $\left(\mathrm{NH}_{2}\right.$ adsorbent) of two fractions containing the FAME and the phytosterols, respectively. In this respect, the fatty acid composition analysis and the determination of phytosterols were combined in terms of sample preparation. The reaction conditions applied to obtain the FAME were optimized to ensure that the sterol esters reacted completely, releasing their free sterol forms. The two fractions, the FAME and phytosterols, were analyzed by GC-FID according to standard methods. Crude and refined oils of different nature, namely, rapeseed, sunflower, and soybean oil, were used in the present study to validate such analytical changes.

\section{Materials and Methods}

\section{Reagents}

$\alpha$-Cholestanol (cholestan-3-ol, $(3 \beta, 5 \alpha) ; \quad$ purity $\geq 95 \%$ ) and $\quad N, O$ bis(trimethylsilyl)trifluoroacetamide (BSTFA) containing $1 \%$ trimethylchlorosilane (TMCS), used as silylating reagent, were purchased from Supelco (Bellefonte, PA, USA). n-Hexane (purity 96\%, HPLC grade), ethyl acetate, diethyl ether, methanol, and 
sodium methoxide (30\%) were supplied by Panreac Química SLU (Castellar del Vallès, Barcelona, Spain). Dichloromethane was purchased from Carlo Erba Reagents S.A.S (Val de Reuil, France), and sulfuric acid (95-97\%) was supplied by Merck (Darmstadt, Germany). Glacial acetic acid was obtained from Quality Chemicals (Esparreguera, Barcelona, Spain).

\section{Samples}

Seed oil samples, namely, rapeseed, sunflower and soybean oils, were supplied by Lesieur (Clichy, France). The rapeseed and sunflower oils were crude oils, whereas the soybean oil was refined. The crude oils were filtered to remove suspended solid particles and moisture. Two rapeseed oils of different batches were used to optimize the conditions applied in the sample preparation. Rapeseed oil 1 and 2 showed acidity values of 1.8 and $1.9 \%$, respectively. As to the soybean oil, the acidity value was $0.05 \%$. Rapeseed oil 1 was also used in the validation of the method.

\section{Standard Method for the Determination of Fatty Acid Composition}

The fatty acid composition was determined by applying IUPAC method 2.301 for the preparation of the FAME and IUPAC method 2.302 for gas-liquid chromatography analysis (IUPAC 1992). An aliquot of 50-mg oil was transmethylated with $5 \mathrm{~mL}$ of $3 \%$ sodium methoxide solution at $80{ }^{\circ} \mathrm{C}$ for $10 \mathrm{~min}$. Then a $5-\mathrm{mL}$ solution of $4 \%$ sulfuric acid in methanol was added and heated at $80{ }^{\circ} \mathrm{C}$ for 10 min to methylate the free fatty acids. The lipid fraction was extracted with $2 \mathrm{~mL}$ of hexane and directly analyzed by GC. A volume of $1 \mu \mathrm{L}$ of the solution was injected in the chromatograph. An Agilent Technologies (AT) 6890 chromatograph was used. This was equipped with a split/splitless injector, an AT INNOWAX capillary column $(100 \mathrm{~m} \times 0.25 \mathrm{~mm}$ i.d. $\times$ $0.25-\mu \mathrm{m}$ film thickness) and a flame ionization detector (FID). The injector temperature 
was set at $225^{\circ} \mathrm{C}$ and a $40: 1$ split ratio was used. Hydrogen at a flow rate of $1.2 \mathrm{~mL} / \mathrm{min}$ was the carrier gas. The analyses were performed by applying an initial temperature of $180{ }^{\circ} \mathrm{C}$ for $9 \mathrm{~min}$. Then the temperature was increased to $220^{\circ} \mathrm{C}$ at $3{ }^{\circ} \mathrm{C} / \mathrm{min}$ and held at $220{ }^{\circ} \mathrm{C}$ for $15 \mathrm{~min}$. The FID temperature was set at $250{ }^{\circ} \mathrm{C}$.

\section{Standard Method for the Analysis of Phytosterols}

Methods IUPAC 2.401 and 2.402 were applied with minor modifications (IUPAC, 1992). Accordingly, $\alpha$-cholestanol was used as IS. The oil (1-2.5 g) was saponified with $2 \mathrm{M}$ alcoholic potassium hydroxide $(50 \mathrm{~mL})$, and the unsaponifiable fraction was extracted by liquid-liquid extraction with diethyl ether. The sterols were isolated by TLC and subjected to silylation with BSTFA containing $1 \%$ TMCS at $80{ }^{\circ} \mathrm{C}$ for $30 \mathrm{~min}$. To guarantee a complete silylation, it was necessary to allow the samples to stand overnight in the reaction medium in a desiccator at room temperature. Then, a volume of 1-mL n-hexane was added and the solution was analyzed by GC. A volume of $1 \mu \mathrm{L}$ of the solution was injected in the chromatograph. An AT 7890A chromatograph was utilized. This was equipped with a programmed temperature vaporizing (PTV) injector, an HP-5 column $(30 \mathrm{~m} \times 0.32 \mathrm{~mm}$ i.d. $\times 0.25-\mu \mathrm{m}$ film thickness $)$ and a FID. A volume of $1 \mu \mathrm{L}$ of the silanized fraction was injected in the chromatograph. The PTV injector was another modification of the method. This operated in the solvent vent mode at an initial temperature of $80{ }^{\circ} \mathrm{C}, 20 \mathrm{psi}$, a septum purge flow of $3 \mathrm{~mL} / \mathrm{min}$ and a vent flow of $50 \mathrm{~mL} / \mathrm{min}$. The injector temperature was kept for $1 \mathrm{~min}$; then, this was increased to $280{ }^{\circ} \mathrm{C}$ at $700{ }^{\circ} \mathrm{C} / \mathrm{min}$ and the initial conditions were reestablished. Hydrogen was used as the carrier gas at a constant pressure of 15 psi. The oven temperature program applied

started at $80{ }^{\circ} \mathrm{C}$ for $1 \mathrm{~min}$; then, the temperature was increased to $200{ }^{\circ} \mathrm{C}$ at $40{ }^{\circ} \mathrm{C} / \mathrm{min}$ and this was held for $3 \mathrm{~min}$, increased again to $300{ }^{\circ} \mathrm{C}$ at $4{ }^{\circ} \mathrm{C} / \mathrm{min}$, and held for $10 \mathrm{~min}$. 
The FID temperature was set at $325^{\circ} \mathrm{C}$. The quantification of the different phytosterols was carried out considering the same response factor as that of the IS.

\section{Method Proposed for Analysis of Fatty Acid Composition and Phytosterols}

\section{Development of Sample Preparation}

Given that fatty acid methyl ester preparation and extraction do not constitute a critical step, the development of sample preparation was primarily focused on phytosterols. Three variables were optimized, namely, sample size (50 and $100 \mathrm{mg}$ oil), methylation time (60 and $120 \mathrm{~min}$ ) and number of sample extraction (1 and 3). The optimization was performed using two crude rapeseed oils obtained in different batches. The total amount of phytosterols was used to determine the more appropriate conditions. The criterion adopted was based upon those conditions that gave rise to the highest amount of total phytosterols and the greatest repeatability.

To confirm that the conditions selected in the sample preparation allowed a complete release of phytosterols from their esterified forms, cholesteryl stearate was added to one of the two crude oils at concentrations that ranged between 300 and $3000 \mathrm{mg} / \mathrm{kg}$. The spiked oil was accordingly analyzed and recovery was determined on a molar basis.

Two SPE cartridges, silica (Si-1 g / $6 \mathrm{~mL})$ and aminopropyl $\left(\mathrm{NH}_{2}-500 \mathrm{mg} / 3 \mathrm{~mL}\right)$ (Agilent Technologies), were tested for the separation of the FAME and phytosterol fractions. The separation efficiency was evaluated by thin-layer chromatography (TLC), which was performed on silica plates (Merck, Darmstadt, Germany). The eluent system was hexane:diethyl ether $(80: 20 \mathrm{v} / \mathrm{v})$ and the fractions were revealed with iodine vapor.

\section{Recommended Analytical Procedure}

An aliquot of 50-mg oil was transmethylated in a screw-cap Pyrex ${ }^{\circledR}$ test tube $(20 \mathrm{~cm} \times$ $20 \mathrm{~mm}$ O.D.) with $5 \mathrm{~mL}$ of $3 \%$ sodium methoxide solution in methanol at $80{ }^{\circ} \mathrm{C}$ for 30 
min. Then for the methylation of FFA, a solution of $4 \%$ sulfuric acid in methanol was added and the reaction was run at $80{ }^{\circ} \mathrm{C}$ for $30 \mathrm{~min}$. Both methanolic solutions were previously purged with a stream of nitrogen during 10 min before use to prevent polyunsaturated fatty acids from oxidative degradation. Also, the reaction tube was flushed with a stream of nitrogen to displace the air in the head space before each reaction and the tube was closed. As in the official method, $\alpha$-cholestanol was used as IS in the analysis of phytosterols $(50 \mu \mathrm{L} ; 0.5 \mathrm{mg} / \mathrm{mL})$. The lipid fraction was extracted three times with n-hexane ( $2 \mathrm{~mL}$ each), washed two times with water ( $2 \mathrm{~mL}$ each) and dried with anhydrous sodium sulfate. Finally, the solvent was evaporated under nitrogen and the derivatized oil was re dissolved in $1 \mathrm{~mL}$ hexane for fractionation by SPE. Aminopropyl cartridges $\left(\mathrm{NH}_{2}-500 \mathrm{mg} / 3 \mathrm{~mL}\right.$ ) (Agilent Technologies) were used. The cartridges were conditioned using, respectively, $3 \mathrm{~mL}$ methanol, $3 \mathrm{~mL}$ acetone and 4 $\mathrm{mL} n$-hexane. A first fraction containing the FAME was eluted with $8 \mathrm{~mL}$ of $\mathrm{n}$ hexane/dichloromethane (90:10, v/v) (fraction A) and a second fraction containing the phytosterols was obtained with $7 \mathrm{~mL}$ of $\mathrm{n}$-hexane/ethyl acetate (40:60, v/v) (fraction $\mathrm{B})$. Fraction A was analyzed directly by GC to determine the fatty acid composition, according to IUPAC method 2.302 (1992). The chromatograph and the GC conditions were the same as those described above for the official method. For the analysis of phytosterols, the solvent of fraction $\mathrm{B}$ was removed at $60{ }^{\circ} \mathrm{C}$ under vacuum in a rotary evaporator. As described above for the official method, the dried extract was silanized with $200 \mu \mathrm{L}$ of BSTFA containing $1 \%$ TMCS at $80{ }^{\circ} \mathrm{C}$ for $30 \mathrm{~min}$, and the sample was stored in a desiccator overnight. Then $1 \mathrm{~mL}$-hexane was added and the solution was analyzed directly by GC. Also, the chromatograph and the chromatographic conditions were the same as those described above for the standard method of phytosterols. As to the injection system, a split-splitless injector was also examined in the split mode with a 
20:1 split ratio and an injection temperature of $275{ }^{\circ} \mathrm{C}$. In this case, the dried extract was not diluted with $1 \mathrm{~mL}$ n-hexane, but directly analyzed. A volume of $2 \mu \mathrm{L}$ was injected in the chromatograph.

\section{Phytosterol Identification}

GC-MS was used for identification purposes. A Finnigan Trace-GC 2000 gas chromatograph coupled to a Polaris-Q Ion trap mass spectrometer (ThermoFinnigan, Austin, TX, USA) operating in full scan and the MS/MS mode was used. The chromatograph was equipped with a split/splitless injector that operated at $290{ }^{\circ} \mathrm{C}$ in the split mode with a 20:1 split ratio. The column used was a Zebron ZB-5ms (Phenomenex, Torrance, CA, USA) fused silica capillary column $(30 \mathrm{~m}$ long $\times 0.25 \mathrm{~mm}$ i.d $\times 0.25-\mu \mathrm{m}$ film thickness). Helium at $1 \mathrm{~mL} / \mathrm{min}$ at constant flow was the carrier gas. The initial temperature was $180{ }^{\circ} \mathrm{C}$, which was kept for $3 \mathrm{~min}$, then raised to $270{ }^{\circ} \mathrm{C}$ at a rate of $8{ }^{\circ} \mathrm{C} / \mathrm{min}$ and held for $46 \mathrm{~min}$, then raised again to $295^{\circ} \mathrm{C}$ at a rate of $4{ }^{\circ} \mathrm{C} / \mathrm{min}$ and held for $8 \mathrm{~min}$. The MS operating conditions were as follows. The electron energy was $70 \mathrm{eV}$ and the scan range used was 60-700 amu. Xcalibur software (version 1.4) was used for data acquisition and processing.

\section{Statistical Analysis}

Analytical determinations were carried out in quintuplicate or, when indicated, in triplicate, and results were expressed as mean values followed by the standard deviation. The experimental design applied for the optimization of the sample preparation conditions was a full factorial design of three factors and two levels. As indicated above, the sample size (50 and $100 \mathrm{mg}$ oil), the total methylation time (60 and $120 \mathrm{~min}$ ), and the number of sample extraction (1 and 3) were the optimized factors. Comparisons between mean values were made by Student's $t$ test in Microsoft Excel 2010 (Microsoft 
Corporation, Redmond, WA, USA). A multivariate general linear model (GLM) in 24.0 SPSS Statistics program (SPSS Inc., Chicago, IL, USA) was applied to examine possible significant differences between the method proposed and the standard methods. The type of oil and the analytical method were considered the independent factors, whereas the type of fatty acid, on the one hand, and the type of phytosterol, on the other, were the dependent factors. The total amount of phytosterol was also considered a dependent variable in the statistical analysis. Due to the fact that the null hypothesis in the variance homogeneity test or Levene's test was not fulfilled for all the analytes, a non-parametric test was also applied in the SPSS program. The U test of Mann-Whitney considering independent samples was the test used. Significance was defined at $p<$ 0.05 .

\section{Results and Discussion}

\section{Optimization of Sample Preparation}

Results showed that the greatest amount of total phytosterols was attained in experiment

2 (Table 1). However, the conditions applied in experiment 2 gave rise to the least values of repeatability. Experiment 6 resulted in the second highest values for the total amount of phytosterols with acceptable repeatability. The coefficient of variation was lower than 3\%. Hence the conditions used in experiment 6 were considered the most appropriate and thereupon were those applied in the method proposed.

The methylation time selected was $60 \mathrm{~min}, 30 \mathrm{~min}$ at basic conditions and $30 \mathrm{~min}$ at acidic conditions. This time was longer compared to that used in the preparation of the FAME in the standard method for the determination of fatty acid composition, which is $20 \mathrm{~min}, 10 \mathrm{~min}$ at basic conditions for the transmethylation reaction followed by $10 \mathrm{~min}$ at acid conditions for the direct reaction of free fatty acids. To test if such a difference could have an influence on the results of the fatty acid composition, rapeseed, 
sunflower, and soybean oils were analyzed by applying both the methylation times, 20 and 60 min. Results showed slight but significant differences (Table 2). A decrease of polyunsaturated fatty acids, i.e., linoleic and linolenic acids, was observed and, consequently, saturated fatty acids, mainly palmitic and stearic acids, significantly increased. This fact can be attributed to the oxidative degradation of the former, which readily react with oxygen giving rise to a number of both non-volatile and volatile compounds (Frankel 2012). To prevent the polyunsaturated fatty acids from oxidation, it was necessary to run the methylation reactions under inert conditions, i.e., using a stream of nitrogen to displace the air dissolved in the reactant solutions and that in the head space of the reaction tube. According to the standard method (IUPAC 1992), when oils or fats are especially susceptible to oxidative degradation, mainly oils and fats containing fatty acids with more than two double bonds, it is advisable to purge the reactants and the reaction flask with nitrogen for a few minutes. This is not usually performed in fats and oils with low acidity, as those used in the present study, but the extended reaction time selected made it necessary. As dealt later, the reactions at inert conditions also improved the repeatability of the determination of fatty acid composition.

In preliminary tests, the type of SPE phase for the separation of the FAME and phytosterol fractions was also studied. The fractionation with silica cartridges was not as reproducible as that attained with an amino phase (not shown). Hopia et al. (1992) also observed similar results in the analysis of lipid classes in edible oils. They suggested that the differences between the two SPE columns were probably due to a greater absorption of moisture in the air on the silica, which is slightly more polar than the amino phase. It was concluded that moisture has less effect on the lipid adsorption capacity of the amino SPE column. 


\section{Optimization of Gas Chromatographic Conditions in the Analysis of Phytosterols}

The type of sample inlet in the gas chromatography analysis of phytosterols was also tested. Two types of injection were examined, a conventional hot split injection and a split programmed temperature vaporizing (PTV) injection or cold split. The chromatograms obtained with the cold split presented more intense signals as a consequence of a concentration effect of the analytes (Fig. 1). The PTV injection exerted a great influence on those phytosterols present in minor amounts, which allowed a more precise determination. As a result, the cold split inlet was the injection mode chosen. For comparative purposes, it was also the injection technique used in the standard method.

A GC-MS analysis was performed to confirm that, under the experimental conditions applied, phytosterols were evaluated as pure compounds, without hidden chromatographic overlapping with other minor compounds. The base MS peaks as well as the qualifiers obtained for each phytosterol are listed in Table 3. Results showed that the phytosterol fraction did not present other compounds interfering in the GC analysis. As reported in other analytical studies, aliphatic alcohols and triterpenic dialcohols, present at variable concentrations in the unsaponifiable fraction of fruit oils like olive oils, might interfere in the analysis of phytosterols by chromatographic overlapping (Mathison and Holstege 2013; Seçmeler and Güçlü Üstündağ 2017). Therefore, the analytical procedure developed in the present study is applicable for the analysis of seed oils but may otherwise find analytical difficulties in more complex samples like oleaginous fruit oils like olive oils and others.

\section{Validation of the Method Proposed}


The validation of the method proposed was based upon the analysis of three different vegetable oils compared to the official methods used for the determination of fatty acid composition and quantification of phytosterols in oils.

\section{Fatty Acid Composition}

The composition of fatty acids did not show significant differences compared to the official method (Table 4). Only significant differences were found for linoleic acid in sunflower oil when Student's $t$ test was applied. The relative level of linoleic acid was slightly higher in the method proposed. However, the difference found was lower than $0.4 \%$, which is quite below the repeatability value of the standard method. Accordingly, the difference between the results of two determinations carried out simultaneously or in rapid succession on the same sample, by the same analyst, under the same conditions, shall not exceed $0.5 \mathrm{~g} / 100 \mathrm{~g}$ of sample or $10 \%$ of the determined value, whichever is the greater (IUPAC 1992). The sample preparation at inert conditions considerably reduced the standard deviation. For those fatty acids present at levels greater than $0.5 \%$, the coefficient of variation was lower than or equal to $1.5 \%$.

\section{Phytosterols}

Similarly to the fatty acid composition, the concentrations of phytosterols were quite similar to those obtained in the official method (Table 5). No significant differences were found between the two methods for the major phytosterols, namely, brassicasterol, campesterol, stigmasterol, and $\beta$-sitosterol or the total amount of phytosterols. With the exception of clerosterol, slight but significant differences were found for those phytosterols present in minor amounts when a global multivariate GLM was applied. Nevertheless, Levene's test showed significance, and a non-parametric test only exhibited significant differences for $\Delta 5,24$-stigmastadienol. 
Repeatability of the method proposed was acceptable. The coefficient of variation was lower than $10 \%$ for the major phytosterols, as well as for their total amount (Table 5). Similar results have been reported by Toivo et al. (1998), who proposed a determination in which a SPE separation of phytosterols was also involved. Remarkably, the coefficient of variation for the total amount of phytosterols was relatively low in the rapeseed oil and similar to that found in the official method $(<1.5 \%)$. Such a result is in agreement with those obtained in the optimization of sample preparation, in which two rapeseed oils were used (Table 1). However, the poor repeatability found for the soybean and sunflower oils is not easy to explain.

The average recovery of cholesteryl stearate added to a rapeseed oil was $94 \%$ on a molar basis at concentrations that ranged between 300 and $3000 \mathrm{mg} / \mathrm{kg}$, which indicated good accuracy of the method. These results also show that the conditions applied in the sample preparation step were sufficient for the complete release of phytosterols from their esterified forms.

\section{Conclusions}

The method proposed in the present study was found to be appropriate for fast determination of fatty acid composition and levels of phytosterols in small amounts of seed oils. Compared to the standard procedures, the time for sample preparation was reduced by half. Thus, the time estimated for preparation of the FAME and phytosterols, up to the derivatization step, was shorter than $4 \mathrm{~h}$, whereas it was almost 7 $\mathrm{h}$ when applying the standard procedures. The results obtained for the main fatty acids and the major phytosterols have shown that the analytical changes introduced provide reliable results in terms of accuracy and repeatability. In addition, the sample preparation is much less laborious, quite convenient, and requires less volume of organic solvents, which reduces considerably the total cost of analysis as well as the 
solvent waste. As a result, it can be used as routine analysis in laboratories of oil quality control in the food industry and in plant breeding studies in which small amounts of oils are to be analyzed.

Funding This work was funded by "Junta de Andalucía" through project P12-AGR4622 and the Spanish Ministry of Economy, Industry and Competitiveness through project AGL2013-45110-R. The authors thank to Irene Pérez de la Rosa for her technical assistance.

\section{Compliance with Ethical Standards}

Conflict of interest Aída García-González declares that she has no conflict of interest. Joaquín Velasco declares that he has no conflict of interest. Leonardo Velasco declares that he has no conflict of interest. M. Victoria Ruiz-Méndez declares that she has no conflict of interest.

Ethical Approval This article does not contain any studies with human participants or animals performed by any of the authors.

Informed Consent Not applicable. 


\section{References}

Abidi SL (2001) Chromatographic analysis of plant sterols in foods and vegetable oils. J Chromatogr A 935(1-2):173-201. https://doi.org/10.1016/S0021-9673(01)009463

Alberici RM, Fernandes GD, Porcari AM, Eberlin MN, Barrera-Arellano D, Fernández FM (2016) Rapid fingerprinting of sterols and related compounds in vegetable and animal oils and phytosterol enriched-margarines by transmission mode direct analysis in real time mass spectrometry. Food Chem 211:661-668. https://doi.org/10.1016/j.foodchem.2016.05.057

AOCS (1997) Method Ch 6-91 in official methods and recommended practices of the American Oil Chemists' Society. AOCS Press, Champaign

Codex Alimentarius (2001) Codex standard for named vegetable oils. CODEX STAN 210-1999

EEC (1991) Commission regulation no 2568/91. Determination of the composition and content of sterols by capillary-column gas chromatography. Official Journal of the European Communities. No. L 248/15-22

Fernández-Cuesta A, Aguirre-González M., Ruiz-Méndez MV, Velasco L (2012) Validation of a method for the analysis of phytosterols in sunflower seeds. EurJ Lipid Sci Technol 114(3):325-331. https://doi.org/10.1002/ejlt.201100138

Frankel E.N. (2012) Free radical oxidation. In: Frankel EN (ed) Lipid oxidation, 2nd edn. Woodhead publishing limited, Cambridge, pp 15-24

Garcés R, Mancha M (1993) One-step lipid extraction and fatty acid methyl esters preparation from fresh plant tissues. Anal Biochem 211(1):139-143. https://doi.org/10.1006/abio.1993.1244 
Gordon MH, Griffith, RE (1992) Steryl ester analysis as an aid to the identification of oils in blends. Food Chem 43(1): 71-78. https://doi.org/10.1016/03088146(92)90244-V

Hopia AI, Piironen VI, Koivistoinen PE, Hyvönen LE (1992) Analysis of lipid classes by solid-phase extraction and high-performance size-exclusion chromatography. $\mathrm{J}$ Am Oil Chem Soc 69:772-776. https://doi.org/10.1007/BF02635913

ISO (1991) Method 6799. Animal and vegetable fats and oils-determination of composition of the sterol fraction-method using gas chromatography. International Organization for Standardization

ISO (1999) Method 12228-2. Determination of individual and total sterols contents-gas chromatographic method. International Organization for Standardization

IUPAC (1992) Standard methods for the analysis of oils, fats and derivatives, $7^{\text {th }}$ edn. International union of pure and applied chemistry, Blackwell Scientific, Oxford

Kumar S, Mawlong I, Singh D (2016) Phytosterol recovery from oilseeds: recent advances. J Food Process Eng 40:e12466. https://doi.org/10.1111/jfpe.12466

Lagarda MJ, García-Llatas G, Farré R (2006) Analysis of phytosterols in foods. J Pharma Biomed Anal 41(5):1486-1496. https://doi.org/10.1016/j.jpba.2006.02.052

Magnusson B, Örnemark U (2014) Eurachem guide: the fitness for purpose of analytical methods-a laboratory guide to method validation and related topics. Available: http://www. eurachem. org [Accessed June 24, 2015].

Mathison B, Holstege D (2013) A rapid method to determine sterol, erythrodiol, and uvaol concentrations in olive oil. J Agric Food Chem 61(19):4506-4513. https://doi.org/10.1021/jf400254k 
Moreau RA, Whitaker BD, Hicks KB (2002) Phytosterols, phytostanols, and their conjugates in foods: structural diversity, quantitative analysis, and healthpromoting uses. Prog Lipid Res 41(6):457-500. https://doi.org/10.1016/S01637827(02)00006-1

Seçmeler Ö, Güçlü Üstündağ Ö (2017) A rapid in-house validated GC-FID method for simultaneous determination of lipophilic bioactives in olive oil: squalene, $\alpha-$ tocopherol, and $\beta$-sitosterol. Eur J Lipid Sci Technol 119(1):1500420. https://doi.org/10.1002/ejlt.201500420

Spencer GF, Herb SF, Gormisky PJ (1976) Fatty acid composition as a basis for identification of commercial fats and oils. J Am Oil Chem Soc 53(3):94-96. https://doi.org/10.1007/BF02635956

Tena N, Wang SC, Aparicio-Ruiz R, García-González DL, Aparicio R (2015) In-depth assessment of analytical methods for olive oil purity, safety, and quality characterization. J Agric Food Chem 63(18):4509-4526. https://doi.org/10.1021/jf5062265

Toivo J, Piironen V, Kalo P, Varo P (1998) Gas chromatographic determination of major sterols in edible oils and fats using solid-phase extraction in sample preparation. Chromatographia 48(11-12):745-750. https://doi.org/10.1007/BF02467642 
Table 1 Optimization of conditions in the analysis of total sterols ( $\mathrm{mg} / \mathrm{kg}$ oil) by the method proposed

\begin{tabular}{llllll} 
Experiment & Sample (mg) & Time (min) & Number of extractions & Rapeseed 1 & Rapeseed 2 \\
\hline $\mathbf{1}$ & 50 & 120 & 3 & $7680 \pm 309$ & $7820 \pm 249$ \\
$\mathbf{2}$ & 100 & 120 & 3 & $8404 \pm 446$ & $8721 \pm 814$ \\
$\mathbf{3}$ & 50 & 120 & 1 & $7729 \pm 71$ & $7618 \pm 104$ \\
$\mathbf{4}$ & 100 & 120 & 1 & $7772 \pm 150$ & $7819 \pm 146$ \\
$\mathbf{5}$ & 50 & 60 & 1 & $7702 \pm 65$ & $7968 \pm 132$ \\
$\mathbf{6}$ & 50 & 60 & 3 & $7939 \pm 219$ & $7985 \pm 70$ \\
$\mathbf{7}$ & 100 & 60 & 1 & $7574 \pm 36$ & $7529 \pm 94$ \\
$\mathbf{8}$ & 100 & 60 & 3 & $7796 \pm 96$ & $7803 \pm 120$ \\
\hline
\end{tabular}

Results are expressed as mean values followed by standard deviation $(n=3)$ 
Table 2 Influence of the methylation time on the fatty acid composition

\begin{tabular}{|c|c|c|c|c|c|c|}
\hline & \multicolumn{2}{|l|}{ Rapeseed oil } & \multicolumn{2}{|l|}{ Sunflower oil } & \multicolumn{2}{|l|}{ Soybean oil } \\
\hline & $20 \mathrm{~min}$ & $60 \mathrm{~min}$ & $20 \mathrm{~min}$ & $60 \mathrm{~min}$ & $20 \mathrm{~min}$ & $60 \mathrm{~min}$ \\
\hline C16:0 & $4.42 \pm 0.02 b$ & $4.57 \pm 0.05 \mathrm{a}$ & $5.95 \pm 0.07 b$ & $6.13 \pm 0.03 a$ & $10.68 \pm 0.16 b$ & $11.39 \pm 0.08 \mathrm{a}$ \\
\hline C16:1 & $0.19 \pm 0.00$ & $0.18 \pm 0.01$ & $0.09 \pm 0.01$ & $0.08 \pm 0.00$ & $0.09 \pm 0.00$ & $0.09 \pm 0.01$ \\
\hline C18:0 & $1.62 \pm 0.02 b$ & $3.52 \pm 0.25 \mathrm{a}$ & $3.33 \pm 0.07 b$ & $4.60 \pm 0.12 \mathrm{a}$ & $3.61 \pm 0.04 b$ & $4.82 \pm 0.08 \mathrm{a}$ \\
\hline C18:1 & $63.47 \pm 0.12$ & $63.66 \pm 0.26$ & $29.32 \pm 0.12 b$ & $30.24 \pm 0.12 \mathrm{a}$ & $25.32 \pm 1.40$ & $25.54 \pm 0.15$ \\
\hline $\mathrm{C} 18: 2$ & $19.21 \pm 0.05 \mathrm{a}$ & $17.98 \pm 0.17 b$ & $60.09 \pm 0.15 \mathrm{a}$ & $57.96 \pm 0.21 b$ & $53.04 \pm 1.08$ & $54.22 \pm 0.19$ \\
\hline C20:0 & $0.57 \pm 0.01$ & $0.58 \pm 0.03$ & $0.37 \pm 0.01 \mathrm{a}$ & $0.29 \pm 0.01 b$ & $0.46 \pm 0.01$ & $0.44 \pm 0.03$ \\
\hline C18:3 & $8.44 \pm 0.05 a$ & $7.67 \pm 0.05 b$ & $0.11 \pm 0.01 \mathrm{a}$ & $0.08 \pm 0.01 b$ & $5.99 \pm 0.11$ & $5.85 \pm 0.08$ \\
\hline C20:1 & $1.82 \pm 0.04 \mathrm{a}$ & $1.59 \pm 0.04 b$ & $0.15 \pm 0.00 \mathrm{a}$ & $0.12 \pm 0.00 b$ & $0.47 \pm 0.01 \mathrm{a}$ & $0.33 \pm 0.01 b$ \\
\hline $\mathrm{C} 22: 0$ & $0.26 \pm 0.01$ & $0.25 \pm 0.01$ & $0.58 \pm 0.01 \mathrm{a}$ & $0.49 \pm 0.01 b$ & $0.35 \pm 0.02$ & $0.30 \pm 0.04$ \\
\hline
\end{tabular}

Results are expressed as mean values followed by standard deviation $(\mathrm{n}=5)$. According to Student's $t$ test, different letters for a given fatty acid show significant differences between the mean values provided by the two analytical methods in each oil $(p<0.05)$ 
Table 3 Mass spectrometry characteristics of sterols in the identification analysis by GC-MS

\begin{tabular}{|c|c|c|c|c|}
\hline Sterol & $\mathbf{M W}^{\mathrm{a}}$ & Derivatize MW & Base peak & Qualifier \\
\hline Cholesterol & 386 & 458 & 368 & 329 \\
\hline Brassicasterol & 398 & 470 & 380 & 365 \\
\hline Campesterol & 400 & 472 & 382 & 343 \\
\hline Stigmasterol & 412 & 484 & 255 & 394 \\
\hline$\Delta 7$-campesterol & 400 & 472 & 472 & 367 \\
\hline Clerosterol & 412 & 484 & 121 & 414 \\
\hline$\beta$-sitosterol & 412 & 486 & 396 & 357 \\
\hline$\Delta 5$-avenasterol & 412 & 484 & 296 & 386 \\
\hline$\Delta 5,24$-stigmastadienol & 412 & 484 & 296 & 414 \\
\hline$\Delta 7$-stigmastenol & 414 & 486 & 213 & 255 \\
\hline$\Delta 7$-avenasterol & 412 & 484 & 343 & 253 \\
\hline
\end{tabular}

${ }^{a}$ Molecular weight 
Table 4 Fatty acid composition (\%) by the standard procedure and the method proposed

\begin{tabular}{lllllll}
\hline & \multicolumn{2}{c}{ Rapeseed oil } & & Sunflower oil & & Soybean oil \\
\cline { 2 - 7 } & Standard & Proposed & Standard & Proposed & Standard & Proposed \\
\hline C16:0 & $4.42 \pm 0.00$ & $4.43 \pm 0.01$ & $5.99 \pm 0.02$ & $5.97 \pm 0.01$ & $10.73 \pm 0.01$ & $10.72 \pm 0.03$ \\
C16:1 & $0.19 \pm 0.00$ & $0.19 \pm 0.00$ & $0.09 \pm 0.00$ & $0.08 \pm 0.01$ & $0.09 \pm 0.00$ & $0.09 \pm 0.01$ \\
C18:0 & $1.83 \pm 0.03$ & $1.81 \pm 0.03$ & $3.61 \pm 0.06$ & $3.57 \pm 0.04$ & $3.59 \pm 0.03$ & $3.57 \pm 0.05$ \\
C18:1 & $63.44 \pm 0.02$ & $63.44 \pm 0.03$ & $29.38 \pm 0.10$ & $29.36 \pm 0.03$ & $24.38 \pm 0.03$ & $24.35 \pm 0.02$ \\
C18:2 & $19.16 \pm 0.01$ & $19.17 \pm 0.02$ & $59.56 \pm 0.02 b$ & $59.77 \pm 0.04 a$ & $53.83 \pm 0.06$ & $53.90 \pm 0.10$ \\
C20:0 & $0.58 \pm 0.00$ & $0.58 \pm 0.00$ & $0.42 \pm 0.11$ & $0.33 \pm 0.01$ & $0.43 \pm 0.01$ & $0.42 \pm 0.01$ \\
C18:3 & $8.28 \pm 0.01$ & $8.28 \pm 0.02$ & $0.11 \pm 0.03$ & $0.09 \pm 0.00$ & $6.04 \pm 0.01$ & $6.05 \pm 0.01$ \\
C20:1 & $1.79 \pm 0.01$ & $1.81 \pm 0.01$ & $0.20 \pm 0.05$ & $0.17 \pm 0.01$ & $0.52 \pm 0.04$ & $0.50 \pm 0.04$ \\
C22:0 & $0.31 \pm 0.01$ & $0.30 \pm 0.03$ & $0.66 \pm 0.00$ & $0.66 \pm 0.00$ & $0.39 \pm 0.02$ & $0.42 \pm 0.06$ \\
\hline
\end{tabular}

Results are expressed as mean values followed by standard deviation $(n=5)$. According to Student's $t$ test, different letters for a given fatty acid show significant differences between the mean values provided by the two analytical methods in each oil $(p<0.05)$ 
Table 5 Analyses of phytosterols $(\mathrm{mg} / \mathrm{kg}$ oil) by the standard procedure and the method proposed

\begin{tabular}{|c|c|c|c|c|c|c|}
\hline & \multicolumn{2}{|c|}{ Rapeseed oil } & \multicolumn{2}{|c|}{ Sunflower oil } & \multicolumn{2}{|c|}{ Soybean oil } \\
\hline & Standard & Proposed & Standard & Proposed & Standard & Proposed \\
\hline Cholesterol* & $41 \pm 5$ & $37 \pm 3$ & nd & nd & $18 \pm 6$ & $12 \pm 2$ \\
\hline Brassicasterol & $806 \pm 4$ & $821 \pm 20$ & nd & nd & nd & nd \\
\hline Campesterol & $3343 \pm 17$ & $3293 \pm 45$ & $412 \pm 14$ & $417 \pm 40$ & $533 \pm 7$ & $538 \pm 48$ \\
\hline Stigmasterol & $31 \pm 8 \mathrm{a}$ & $21 \pm 1 b$ & $344 \pm 5$ & $362 \pm 38$ & $499 \pm 5$ & $531 \pm 53$ \\
\hline$\Delta 7$-campesterol $*$ & $45 \pm 5 \mathrm{a}$ & $33 \pm 6 b$ & $64 \pm 12 \mathrm{a}$ & $34 \pm 9 b$ & nd & nd \\
\hline$\Delta 5,23$-stigmastadienol $*$ & $24 \pm 4 b$ & $48 \pm 2 \mathrm{a}$ & $91 \pm 3$ & $92 \pm 13$ & nd & nd \\
\hline Clerosterol & $40 \pm 6 b$ & $59 \pm 2 \mathrm{a}$ & $44 \pm 2$ & $36 \pm 14$ & nd & nd \\
\hline$\beta$-sitosterol & $4077 \pm 72$ & $4115 \pm 55$ & $2656 \pm 84$ & $2684 \pm 203$ & $1642 \pm 54$ & $1608 \pm 142$ \\
\hline$\Delta 5$-avenasterol $*$ & $281 \pm 6 a$ & $253 \pm 4 b$ & $179 \pm 4$ & $184 \pm 15$ & $41 \pm 9 \mathrm{a}$ & $29 \pm 5 b$ \\
\hline$\Delta 5,24$-stigmastadienol $* * * *$ & $28 \pm 2 b$ & $57 \pm 5 \mathrm{a}$ & $56 \pm 5 b$ & $76 \pm 7 \mathrm{a}$ & $49 \pm 6$ & $44 \pm 3$ \\
\hline$\Delta 7$-stigmasterol ${ }^{*}$ & $10 \pm 3 b$ & $36 \pm 12 \mathrm{a}$ & $414 \pm 4 b$ & $494 \pm 31 \mathrm{a}$ & $93 \pm 1 b$ & $105 \pm 6 a$ \\
\hline$\Delta 7$-avenasterol $*$ & $7 \pm 2$ & $8 \pm 1$ & $172 \pm 2$ & $198 \pm 25$ & $43 \pm 3$ & $48 \pm 5$ \\
\hline Total & $8732 \pm 105$ & $8781 \pm 96$ & $4434 \pm 107$ & $4577 \pm 380$ & $2917 \pm 63$ & $2916 \pm 261$ \\
\hline
\end{tabular}

Results are expressed as mean values followed by standard deviation $(\mathrm{n}=5)$. According to student's $\mathrm{t}$ test, different letters for a given phytosterol show significant differences between the mean values provided by the two analytical methods in each oil $(p<0.05)$. *Significant differences between the methods according to a multivariate GLM analysis $(p<0.05)$. **Significant differences between the methods according to the non-parametric test known as the U test of Mann-Whitney for independent samples $(p<0.05)$

nd, not detected 


\section{Figure captions}

Fig. 1 GC chromatograms of phytosterols obtained using a cold split inlet with a PTV injection system (a) and a hot split in a split-splitless injector (b). Peak assignment: 1, cholesterol; 2, cholestanol; 3, brassicasterol; 4, campesterol; 5, stigmasterol; $\mathbf{6}, \Delta 7$ campesterol; $\mathbf{7}, \quad \Delta 5,23$-stigmastadienol; $\mathbf{8}$, clerosterol; $\mathbf{9}, \quad \beta$-sitosterol; $\mathbf{1 0}, \quad \Delta 5$ avenasterol; 11, $\Delta 5,24$-stigmastadienol; 12, $\Delta 7$-stigmastenol; 13, $\Delta 7$-avenasterol 

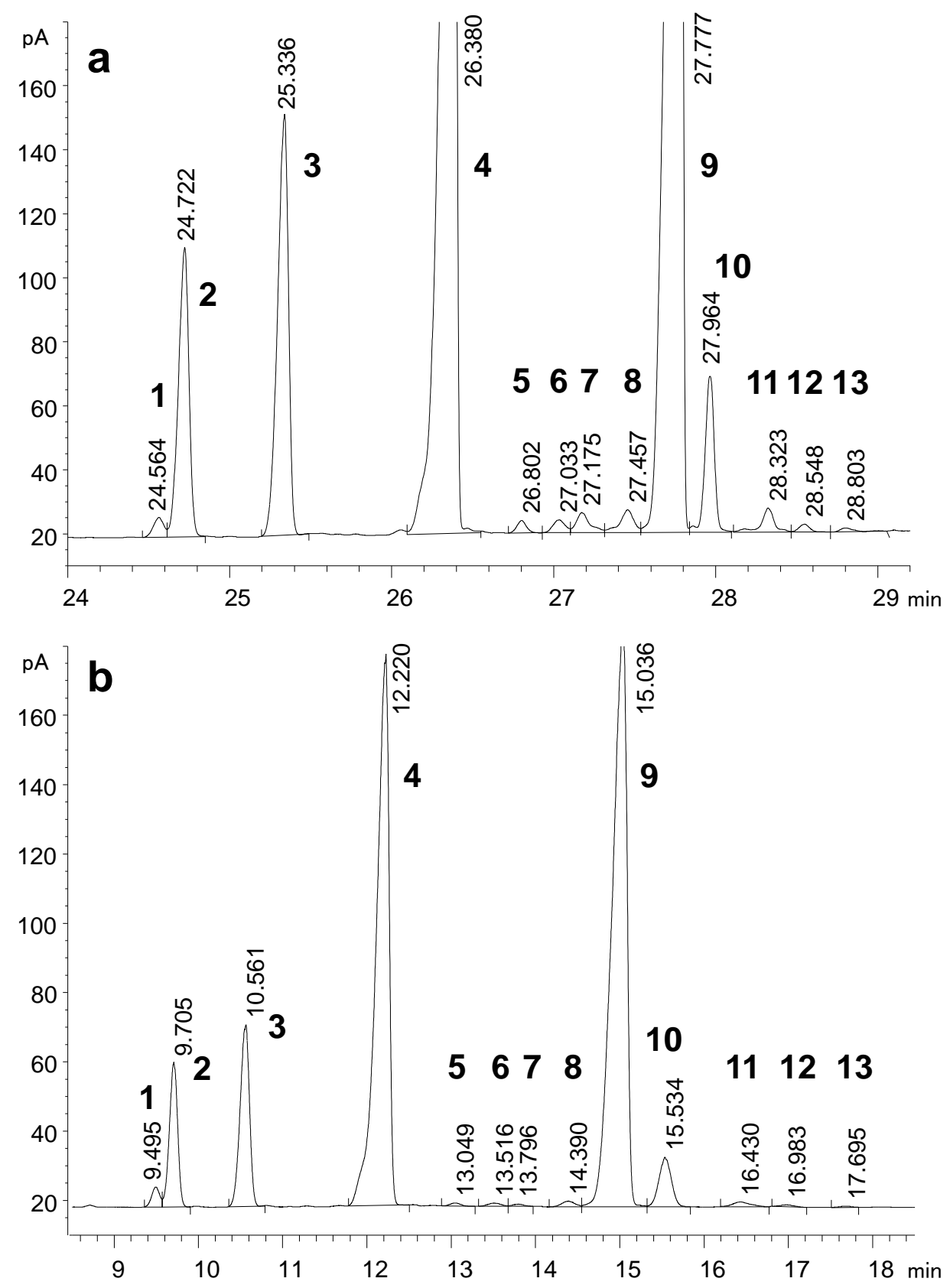

Figure 1 